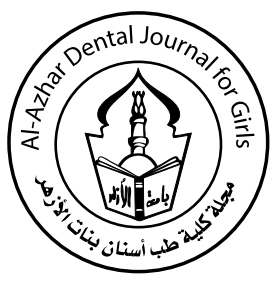

\title{
Masticatory Efficiency Evaluation in Implant Retained Complete Overdenture With Different Occlusal Schemes
}

\author{
Mostafa I. Fayad ${ }^{(1)}$, Ihab I Mahmoud ${ }^{(1)}$, Mohamed A Ismaiel ${ }^{(2)}$, \\ Nehad Harby ${ }^{(1)}$, Mohammed A Quassem ${ }^{(1)}$ and Hassan Sakr ${ }^{(3)}$
}

Codex : 10/1601

dentaljournal.forgirls@yahoo.com

\section{KEYWORDS}

Masticatory efficiency;

acrylic dentures,

bilateral balanced occlusion,

median lingualized occlusion.

\begin{abstract}
Objective: This study was conducted to evaluate the masticatory efficiency in immediately loaded implant retained mandibular complete over denture with two different occlusal schemes namely opposing conventional maxillary complete denture. Patients and Methods: Fourteen completely edentulous patients with age ranged from 51-61 years were selected from outpatient clinic of Removable Prosthodontics, Faculty of Dental Medicine, Al-Azhar University. One stage octa titanium implants with $3.75 \mathrm{~mm}$ diameter and $14 \mathrm{~mm}$ length were used. All Patients sharing in this study receive immediately loaded implant reteined mandibular overdenture. They were randomly divided into two equal groups ( 7 patients in each), the first group had the artificial teeth arranged in a median lingualized occlusio, while the second group had the artificial teeth arranged in a bilateral balanced occlusion. Masticatory efficiency measurements were taken at the first time of overdenture placement and after six months of over denture use. Paired t-test was used to evaluate the masticatory efficiency before and after adaptation period for each group. Independent t-test was used to compare the masticatory efficiency measurements between both groups. Results: At the time of denture placement, there was no significance difference in masticatory efficiency measurements between both groups. Masticatory efficiency was increased considerably after six months of denture use, and it was significantly higher than masticatory efficiency recorded at the time of new prosthesis placement in the same group. After six months of denture use, there was a significance difference in masticatory efficiency measurements between both groups. Conclusions: It was concluded that using lingualized occlusion concepts was resulted in increased masticatory efficiency more than bilateral balanced occlusion after six months of denture use in patients received immediately loaded implant retained mandibular overdenture with ball and socket attachment.
\end{abstract}

1. Lecturer of Removable Prosthodontics, Faculty of Dental Medicine, Al-Azhar University, Egypt

2. Assistant Professor of Removable Prosthodontics, College of Dentistry, Taief University. Saudi Arabia

3. Assistant Professor of Removable Prosthodontics, Faculty of Dental Medicine, Al-Azhar University, Egypt 


\section{INTRODUCTION}

Effective masticatory function is one of the important goals of prosthodontic rehabilitation ${ }^{(1)}$.Reduced masticatory efficiency is one of major complaints of edentulous patients wearing conventional dentures. In addition, the complex neuromuscular skills required to overcome the limitations of dentures diminish with aging. Although there has been an increase in rehabilitation with osseo-integrated implants, treatment with conventional complete dentures still remains the most common treatment for edentulous patients especially in low developed countries ${ }^{(2)}$.

The low masticatory efficiency of denture prostheses impairs the ability of wearers to consume high-fiber foods. Hence, dentures with high masticatory efficiency are required ${ }^{(3)}$.it also has consequences on both physical measures of general health and perceived general health status, as measured using generic health-related quality of life instruments ${ }^{(4)}$.

Chewing function can be assessed using chewing tests and questionnaires or personal interviews $s^{(4,5)}$. Methods used for evaluating masticatory performance have been broadly divided into either subjective methods or objective methods. The former are implemented through various questionnaires, while the latter indicate the condition of the chewed mastication material with a numerical value ${ }^{(6)}$.

Though a number of objective methods of evaluating masticatory performance have been attempted, they require specific instruments, materials, or complicated procedures ${ }^{(7-10)}$. Both natural foods, such as peanuts, almonds and carrots, and synthetic materials have been used as test materials in experiments determining the masticatory performance ${ }^{(5)}$.

Another method to determine masticatory performance, which is now widely used, evaluates the ability to mix and knead a food bolus. Twocoloured chewing gum and paraffin wax have been used as test foods for the quantification of the masticatory performance ${ }^{(5,11)}$.

Color-changeable chewing gum has been developed by a Japanese research group to allow for a simple measurement of masticatory performance through the color change of the chewing gum. The material is specially developed for that purpose (Masticatory Performance Evaluating Gum XYLITOL; Lotte Co., Ltd., Tokyo, Japan) ${ }^{(12)}$.

Tarkowska et al. ${ }^{(13)}$, mentioned that a measurement technique by means of a colorchangeable chewing gum seems most likely to fulfill masticatory efficiency test requirements due to its simplicity and its reported superior differentiability.

Chewing gums that changes its color as it is chewed were chosen as a test food for evaluating masticatory performance as it is used easily by the dentist at the chair side in the clinic with better compliance from patient ${ }^{(14)}$. Colorimetric methods using color scales are inexpensive and simple to use. Furthermore, this method offers the advantage that the subjects can evaluate their own masticatory performance at any location ${ }^{(6)}$.

Color-changeable chewing gum can be used as a stand-alone instrument for perceived chewing ability evaluation because it is a valid and reliable method for the evaluation of masticatory function ${ }^{(6,}$ 13) . These tests have proven more accurate than subjective questionnaire-based methods that collect information on the opinions reported by both patient and professional ${ }^{(15)}$.

In complete denture wearers, the ability to comminute food during mastication is reduced compared to adults with natural dentition, depending on the individual's age and type of food chewed owing to the biomechanical characteristics of exclusively mucosa-supported dentures ${ }^{(15)}$.

The chewing forces used by denture wearers may be limited by the discomfort and the pain that happens when one or both of the dentures lose their retention, or even by the fear of such pain ${ }^{(16)}$. 
In an effort to improve the masticatory efficiency of complete denture wearers, three principal factors; retention, stability, and support should be considered for successful complete dentures. Treatment alternatives that aid in increasing retention and stability for improving denture function should be considered when conventional denture therapy is inadequate $^{(17)}$.

Some people do not succeed in acquiring new skills with their dentures and thus suffer psychologically because of impaired function, comfort, self-image and social interaction. These patients can be successfully treated with implantretained overdentures. Several studies reported the clear benefits of overdenture treatment, versus the conventional denture for a number of aspects such as: aesthetics, speech, chewing, fit and retention, function and quality of life specially the lower ridge $^{(18)}$.

The two-implant mandibular overdenture provides greater retention than does a conventional mandibular denture and, due to its efficacy, can significantly improve an edentulous patient's quality of life $\mathrm{e}^{(19)}$.

The stability of the overdentures retained by two implants was excellent, and the lingual dimensions of the denture could be reduced to the level of the mylohyoid line to provide more space for the tongue $^{(20)}$.

The combination of a mandibular implantsupported or implant retained overdenture and maxillary conventional complete denture (CD) provides significant improvement in masticatory performance compared to CDs in both the mandible and maxilla ${ }^{(21,22)}$.

A study of chewing efficiency compared wearers of conventional complete dentures with wearers of implant-supported overdentures. The complete denture group needed 1.5 to 3.6 times the number of chewing strokes compared with the overdenture group $^{(23,24)}$.
Bilaterally balanced occlusion provides primary stability of the dentures during functional loading and favors equilibration of occlusal loads due to simultaneous contacts on the working and nonworking sides ${ }^{(25,26)}$.

lingualized occlusion has many advantages as it applies to implant supported removable restorations include; occlusal forces that are centered over the ridge crest in centric relation, effective transfer of forces more "lingual" to the ridges during working side excursions and minimized occlusal disharmonies created from errors in jaw registrations, denture processing changes and / or eventual settling of the denture base. Additionally, the "mortar and pestle" type of occlusion minimizes the occlusal contact area and provides more efficient bolus penetration, while minimizing destructive horizontal forces ${ }^{(27-29)}$.

The main advantages attributed to a lingualized occlusion are the absence of deflective occlusal forces between opposing teeth and the relatively natural appearance of the semi-anatomical posterior teeth $^{(30,31)}$.

The present study is one of the few studies comparing masticatory efficiency between median lingualized occlusion and bilateral balanced occlusion in implant retained mandibular complete over denture opposing maxillary denture at the time of new denture placement and after six months.

\section{PATIENTS AND METHODS}

Fourteen completely edentulous patients with age ranged from 51-61 years (mean $53 \mathrm{Y}$ ) were selected from Removable Prosthodontic Out patient clinic, Faculty of Dental Medicine, Al-Azhar University. Informed consent was obtained from all subjects after an explanation of the methodology prior to enrolment in the study. The patients were free from any systemic or local diseases that make the placement of the dental implants contraindicated. 
Patients sharing in this study were randomly divided into two equal groups: Group A: Patients recived a new complete denture with a bilateral balanced occlusion. Group B: Patients recived a new complete denture with a balanced median lingualized occlusion. (figure 1)

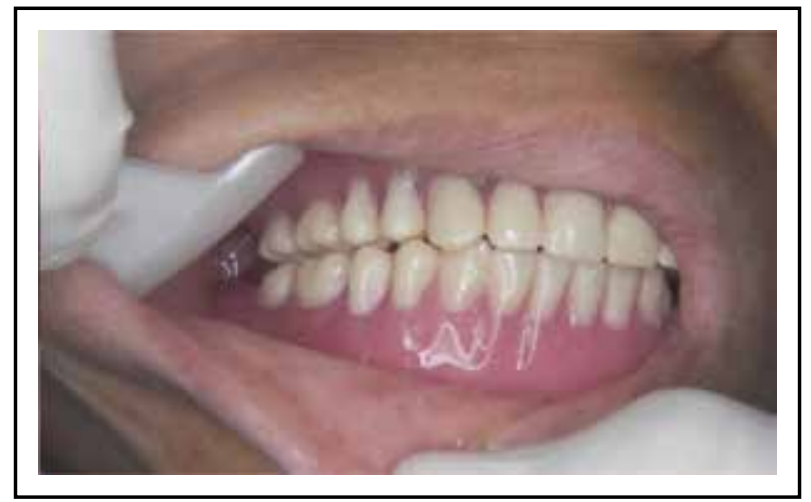

Fig. (1) Finished denture in place with median lingualized occlusion.

New upper and lower complete dentures were constructed as usual manner with specific occlusal scheme according to the patient group. The patient received the new conventional complete denture with even occlusion and free from discomfort. Patient was left for two months to be adapted to the new denture.

The following procedures were carried out for each patient: Diagnostic casts were made in alginate impression (Cavex, Holland) with dental stone (Elite Rock, Zhermack, Italy), and panoramic $\mathrm{X}$-Ray film was taken (Vatech,Yongin-si, Korea) to aid in analysis of jaw relationships, inter arch distance as well as positions of implant.

Each patient received two immediately loaded implants (SwishPlant, Implant Direct, Las Vegas, USA) with $3.75 \mathrm{~mm}$ diameter and $14 \mathrm{~mm}$ length. The implant is cylinder with reversed screw and hydroxyapetite coat.

After 48 hours of implant insertion, ball head abutment driver was used to insert ball head abutment with $2 \mathrm{~mm}$ colar. The metal housing with rubber O-rings were incorporated into the ball abutments and the mandibular denture was checked for stability over the two ball abutment. Undercuts under the sockets were blocked out with soft wax. Immediately loaded implant with ball and socket attachment. (Figure 2)

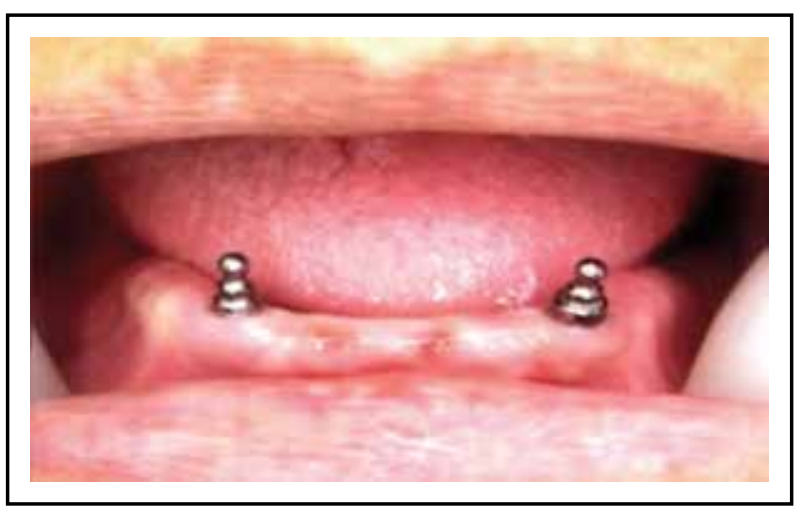

Fig. (2) The two ball attachments in place.

\section{Denture insertion}

The mandibular denture was prepared for reciving the ball and socket attachment then inserted into the patient mouth and the patient was asked to bite forcibly on the mandibular denture at centric occlusion with Pink self cured acrylic resin (Vertex, Vertex-Dental B.V. Asia Pte Ltd, Zeist, Netherlands) in socket holes until complete setting of the acrylic resin.

\section{Masticatory effieviency evaluation}

The test item used for this study was a colourchangeable chewing gum (XYLITOL; Lotte Co., Ltd., Tokyo, Japan) The gum inside the packaging. (Fig. 3) The chewing gum (dimensions, $70 \times 20 \times 1$ $\mathrm{mm}$; weight, $3.0 \mathrm{~g}$ ) initially shows a yellowish-green colour. The color of chewed gum was compared to the color scale provided by the manufacturer ${ }^{(14)}$.

\section{Measurement of masticatory performance using color changeable chewing gum}

I- First measurement was done using chewing gum after first time of overdenture placement. 
II- Second measurement was done after six months of overdenture placement as Goiato ${ }^{(2)}$ suggested that more than five months was needed to evaluate patient adaptation and functional capacity with new complete dentures.

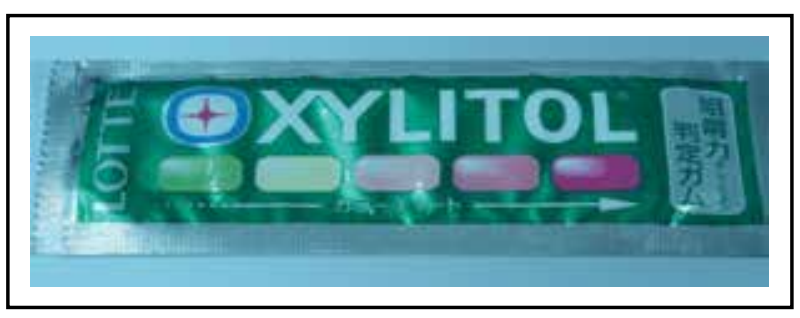

Fig. (3) Colour-changeable chewing gum (Masticatory Performance Evaluating Gum XYLITOL*).

The patients were instructed to, "Please chew the chewing gum well", without being given any instructions with regard to chewing side. Each subject was instructed to chew the gum irrespective of chewing side, for the instructed number of strokes. The patients rinsed their mouths with water for $15 \mathrm{~s}$ before chewing the gum for 100 strokes on their preferred side at a rate of one stroke per second, and this sequence was repeated three times with 30minutes' intervals. A mean value of three trials was used in analysis. After each trial the subjects were asked to rinse their mouth with water. The chewing gum was picked immediately after chewing then compressed between two glasses to evaluate its color ${ }^{(14,32,33)}$.

The chewed bolus was assigned numeric scores according to the degree of color change; $0 \%$ (green), $25 \%$ ( yellow), $50 \%$ (pale pink), $75 \%$ (pink), and $100 \%$ (red). One examiner performed all of color reading. The difference in masticatory efficiency after sex months was calculated and the mean of two groups was compared. Statistical analysis was completed using SPSS software V.20.

\section{RESULTS}

The masticatory efficiency with different occlusal schemes in implant retained mandibular complete over denture was evaluated.

\section{First measurement}

The mean value of color scale scores with bilateral balanced occlusion was $35.7 \pm 12.07$. The mean value of color scale scores with median lingualized occlusion was $36.3 \pm 12.25$. The independent t-test revealed that there was no statistical difference was found between both groups $(p>0.05)$, at the time of new denture placement. (Table 1, Fig. 4)

Table (1) Masticatory efficiency evaluation at the time of denture placement.

\begin{tabular}{|c|c|c|c|c|c|}
\hline \multicolumn{2}{|c|}{ Grouping } & Mean & $\begin{array}{c}\text { Std. } \\
\text { Deviation }\end{array}$ & $\begin{array}{c}\text { Std. } \\
\text { Error } \\
\text { Mean }\end{array}$ & $\begin{array}{c}\text { Sig. } \\
\text { (2-tailed) }\end{array}$ \\
\hline \multirow{2}{*}{ Mast_0 } & G1 & 35.75 & 12.07 & 1.9 & .819 \\
\cline { 2 - 6 } & G2 & 36.37 & 12.25 & 1.9 & \\
\hline
\end{tabular}

G1: Bilateral balanced occlusion.

G2: Median lingualized occlusion.

\section{Second measurement}

The mean value of color scale scores with bilateral balanced occlusionwas39.3 \pm 14.8 . The mean value of color scale scores with median lingualized occlusion was $47.5 \pm 11.03$. After six months, the independent t-test revealed that there was a statistical difference was found between both groups ( $>00.01$ ). (Table 2, Fig. 4)

Table (2) Masticatory efficiency evaluation after six months of denture placement.

\begin{tabular}{|c|c|c|c|c|c|}
\hline & Grouping & Mean & $\begin{array}{c}\text { Std. } \\
\text { Deviation }\end{array}$ & $\begin{array}{c}\text { Std. } \\
\text { Error } \\
\text { Mean }\end{array}$ & $\begin{array}{c}\text { Sig. } \\
\text { (2-tailed) }\end{array}$ \\
\hline \multirow{2}{*}{ Mast_6 } & G1 & 39.37 & 14.85 & 2.34 & $.0 .007^{*}$ \\
\cline { 2 - 6 } & G2 & 47.50 & 11.03 & 1.74 & \\
\hline
\end{tabular}

G1: Bilateral balanced occlusion.

G2: Median lingualized occlusion. 


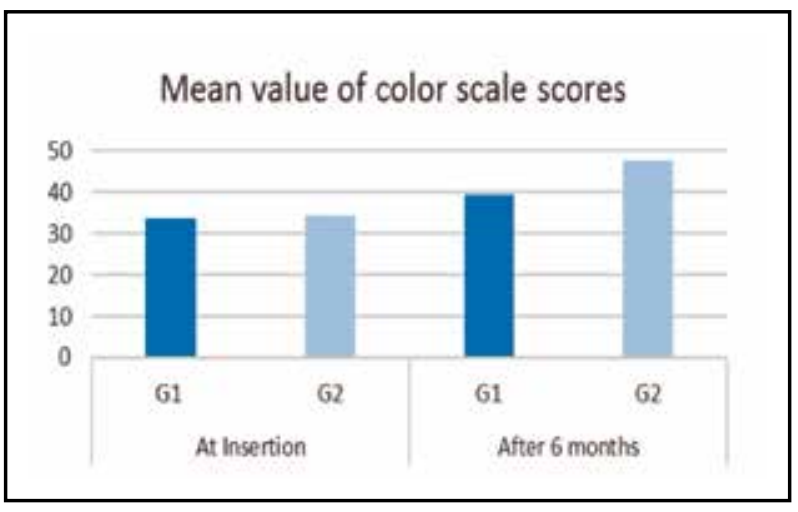

Fig. (4) Mean value of color scale scores for the two groups at denture insertion and after six months.

The paired $\mathrm{t}$ test showed that there was a statistical significance difference was found between the mean value of color scale scores recorded at new denture placement and after six months in both groups. (Table 3 )

Table (3) Paired Samples Statistics for both groups.

\begin{tabular}{|l|c|c|c|c|c|}
\hline \multicolumn{2}{|c|}{} & Mean & $\begin{array}{c}\text { Std. } \\
\text { Deviation }\end{array}$ & $\begin{array}{c}\text { Std. } \\
\text { Error } \\
\text { Mean }\end{array}$ & $\begin{array}{c}\text { Sig. } \\
\text { (2-tailed) }\end{array}$ \\
\hline \multirow{2}{*}{ Pair 1 } & Bilateral_0 & 35.75 & 12.07 & 1.90 & \\
\cline { 2 - 6 } & Bilateral_6 & 39.37 & 14.85 & 2.34 & $0.010^{*}$ \\
\hline \multirow{2}{*}{ Pair 2 } & Lingualized_0 & 36.37 & 12.25 & 1.93 & $0.000^{* *}$ \\
\cline { 2 - 6 } & Lingualized_6 & 47.50 & 11.03 & 1.74 & \\
\hline
\end{tabular}

\section{DISCUSSION}

At the first thought, natural test foods may be considered advantageous because of their consumption in daily lives and familiarity with them. However, this issue can vary according to seasonal and geographical factors.(34)In order to avoid this kind of variability in assessing chewing function, some researchers report that the use of synthetic food is a good alternative ${ }^{(35-37)}$.
Plesh et al. ${ }^{(38)}$ preferred chewing gum as the test material because of the uniform density during chewing cycle. Hayasaki et al. ${ }^{(39)}$ and Shiga et al. ${ }^{(40)}$ also used chewing gum in their studies. Tokmakci et al. ${ }^{(34)}$ mentioned that chewing gum is a material with uniform properties so it can be reliably reproduced and provide an ideal test bolus for the scientific study of masticatory effectiveness. In some previous studies, Blissett et al. ${ }^{(41)}$; Mazari et al. ${ }^{(42)}$ used chewing gum to simplify and standardize the test procedures.

Tokmakci et al. ${ }^{(34)}$ offered sugar-free chewing gum to participants, as it can be applied easily and being sugar- and/or sweetener-free it will not cause salivary stimulation that can influence the mastication function. Further, with its uniform properties in terms of weight and shape, this type of test food has also helped us standardize masticatory efficiency measurements.

The result of the present study found that there was statistical significant difference of the masticatory efficiency between bilateral balanced occlusion and median lingualized occlusion on using color changeable gum (at six months after denture placement). while at the time of denture insertion there was no statistical significant difference between the two groups.

The result of the present study could be explained by the studies of Slagter and Fontijn-Tekamp, they found that masticatory function of the completedenture wearers is quite poor in comparison with that of healthy dentate subjects ${ }^{(43,44)}$.

Mancuso $^{(45)}$ mentioned that the occlusal design and cusp angulations have a direct effect on masticatory efficiency as well as stress transmission into the bone.

Complete-denture wearers need up to 7 times more chewing strokes than subjects with a complete natural dentition to reduce the food to half of the original particle size. Oral function significantly improves after mandibular implant overdenture treatment. Most studies on implant treatment and oral function showed a significant improvement 
of the objective masticatory performance in the mandibular overdenture. ${ }^{(46)}$

The significant lower masticatory efficiency in patients rehabilitated with bilateral balanced occlusion (G1) has been reported in other studies ${ }^{(47)}$.

Chen et al. (48) assessed the comparative masticatory efficiency (CME) of mandibular implant-supported overdentures (ISOs) to toothsupported overdentures (TSOs) and complete dentures (CDs)and they found that the ISO provided the greatest degree of efficiency, followed by the TSO and then the CD group.

The effect of flexible acrylic resin on masticatory muscle activity in implant-supported mandibular overdentures was evaluated and it was found that the use of bilateral balanced occlusion in implantsupported mandibular overdentures resulted in decreased masticatory muscle activity ${ }^{(49)}$.

A significant improvement was observed in the masticatory function with bilateral balanced occlusion and median lingualized occlusion after six months, this may be attributed to increase adaptation and subsequent stability of the denture after six months of denture use.

A statistically significant difference was found after six months between the two groups. These results were in accordance with the study conducted by Hazari et al. ${ }^{(50)}$. These findings may be attributed to the features of median lingualized occlusion and it provides a significant improvement in terms of stability and retention for patients with severe adaptation problems to conventional mandibular dentures. these results were in accordance with the study conducted by Berretin-Felix et al. ${ }^{(51)}$ who mentioned that the type of dental treatment used has a direct relationship with masticatory efficiency.

It is also important to emphasize the diagnostic factor and previous planning before denture construction. The human factor in planning and technical performance are decisive for the success of rehabilitations.

\section{CONCLUSION}

Within the limitations of the present study, the median lingualized occlusion after six months of overdenture placement showed better masticatory efficiency with statistically significant difference than bilateral balanced occlusion in implant retained complete overdenture.

\section{REFERENCES}

1. Liang S, Zhang Q, Witter DJ, Wang Y, Creugers NH. Effects of removable dental prostheses on masticatory performance of subjects with shortened dental arches: A systematic review. J Dent. 2015;43(10):1185-94.

2. Goiato MC, Garcia AR, Dos Santos DM, Zuim PR. Analysis of masticatory cycle efficiency in complete denture wearers. J Prosthodont. 2010;19(1):10-3.

3. Hashimoto Y, Sugimoto K, Tanaka Y, Oki K, Minagi S. A new occlusal surface design for artificial posterior teeth to achieve high masticatory performance. J Prosthodont Res. 2016.

4. Baba K, John MT, Inukai M, Aridome K, Igarahsi Y. Validating an alternate version of the chewing function questionnaire in partially dentate patients. BMC Oral Health. 2009;9:9.

5. van der Bilt A. Assessment of mastication with implications for oral rehabilitation: a review. J Oral Rehabil. 2011; 38(10):754-80.

6. Kamiyama M, Kanazawa M, Fujinami Y, Minakuchi S. Validity and reliability of a Self-Implementable method to evaluate masticatory performance: use of colorchangeable chewing gum and a color scale. J Prosthodont Res. 2010;54(1):24-8.

7. Goiato MC, Ribeiro Pdo P, Garcia AR, dos Santos DM. Complete denture masticatory efficiency: a literature review. J Calif Dent Assoc. 2008;36(9):683-6.

8. van der Bilt A, Fontijn-Tekamp FA. Comparison of single and multiple sieve methods for the determination of masticatory performance. Arch Oral Biol. 2004;49(3): 193-8.

9. Cunha TR, Della Vecchia MP, Regis RR, Ribeiro AB, Muglia VA, Mestriner W, Jr., et al. A randomised trial on simplified and conventional methods for complete denture fabrication: masticatory performance and ability. J Dent. 2013;41(2):133-42. 
10. Liedberg B, Owall B. Oral bolus kneading and shaping measured with chewing gum. Dysphagia. 1995;10(2):101-6.

11. Salleh NM, Fueki K, Garrett NR, Ohyama T. Objective and subjective hardness of a test item used for evaluating food mixing ability. J Oral Rehabil. 2007;34(3):174-83.

12. Hayakawa I, Watanabe I, Hirano S, Nagao M, Seki T. A simple method for evaluating masticatory performance using a color-changeable chewing gum. Int J Prosthodont. 1998;11(2):173-6.

13. Tarkowska A, Katzer L, Ahlers MO. Assessment of masticatory performance by means of a color-changeable chewing gum. J Prosthodont Res. 2016.

14. Ishikawa Y, Watanabe I, Hayakawa I, Minakuchi S, Uchida T. Evaluations of masticatory performance of complete denture wearers using color-changeable chewing gum and other evaluating methods. J Med Dent Sci. 2007; 54(1):65-70.

15. Barbosa WF, Iegami CM, Uehara PN, Furuyama RJ, Tamaki R. In Vivo Comparison of the Masticatory Efficiency of Artificial Teeth with Two Different Cusp Heights in Complete Dentures: A Preliminary Study. J Prosthodont. 2015.

16. Tatematsu M, Mori T, Kawaguchi T, Takeuchi K, Hattori M, Morita I, et al. Masticatory performance in 80-year-old individuals. Gerodontology. 2004;21(2):112-9.

17. Mohamed GF. Clinical evaluation of the efficacy of soft acrylic denture compared to conventional one when restoring severely resorbed edentulous ridge. Cairo Dental Journal. 2008;24(2):313-23.

18. Pierrisnard L, Hure G, Barquins M, Chappard D. Two dental implants designed for immediate loading: a finite element analysis. Int J Oral Maxillofac Implants. 2002;17(3):353-62.

19. Att W, Stappert C. Implant therapy to improve quality of life. Quintessence Int. 2003;34(8):573-81.

20. Cune M, van Kampen F, van der Bilt A, Bosman F. Patient satisfaction and preference with magnet, bar-clip, and ballsocket retained mandibular implant overdentures: a crossover clinical trial. Int J Prosthodont. 2005;18(2):99-105.

21. Fueki K, Kimoto K, Ogawa T, Garrett NR. Effect of implant-supported or retained dentures on masticatory performance: a systematic review. J Prosthet Dent. 2007;98(6):470-7.

22. Bakke M, Holm B, Gotfredsen K. Masticatory function and patient satisfaction with implant-supported mandibular overdentures: a prospective 5-year study. Int J Prosthodont. 2002;15(6):575-81.
23. van Kampen FM, van der Bilt A, Cune MS, FontijnTekamp FA, Bosman F. Masticatory function with implantsupported overdentures. J Dent Res. 2004;83(9):708-11.

24. van der Bilt A, van Kampen FM, Cune MS. Masticatory function with mandibular implant-supported overdentures fitted with different attachment types. Eur J Oral Sci. 2006;114(3):191-6.

25. Farias Neto A, Mestriner Junior W, Carreiro Ada F. Masticatory efficiency in denture wearers with bilateral balanced occlusion and canine guidance. Braz Dent $\mathbf{J}$. 2010;21(2):165-9.

26. Rehmann $\mathrm{P}$, Balkenhol $\mathrm{M}$, Ferger $\mathrm{P}$, Wostmann B. Influence of the occlusal concept of complete dentures on patient satisfaction in the initial phase after fitting: bilateral balanced occlusion vs canine guidance. Int J Prosthodont. 2008;21(1):60-1.

27. Becker CM, Swoope CC, Guckes AD. Lingualized occlusion for removable prosthodontics. J Prosthet Dent. 1977;38(6):601-8

28. Phoenix RD, Engelmeier RL. Lingualized occlusion revisited. J Prosthet Dent. 2010;104(5):342-6.

29. Garcia LT, Bohnenkamp DM. Lingualized occlusion: an occlusal solution for edentulous patients. Pract Proced Aesthet Dent. 2005;17(9):5 pages preceding page 633.

30. Kimoto S, Gunji A, Yamakawa A, Ajiro H, Kanno K, Shinomiya M, et al. Prospective clinical trial comparing lingualized occlusion to bilateral balanced occlusion in complete dentures: a pilot study. Int $\mathbf{J}$ Prosthodont. 2006;19(1):103-9.

31. Folz S, Byars B. Lingualized bilateral balanced occlusion complete dentures constructed on fixed articulators. Tex Dent J. 1981;99(10):12-7.

32. Hama Y, Kanazawa M, Minakuchi S, Uchida T, Sasaki Y. Reliability and validity of a quantitative color scale to evaluate masticatory performance using color-changeable chewing gum. J Med Dent Sci. 2014;61(1):1-6.

33. Hama Y, Kanazawa M, Minakuchi S, Uchida T, Sasaki Y. Properties of a color-changeable chewing gum used to evaluate masticatory performance. J Prosthodont Res. 2014;58(2):102-6.

34. Tokmakci M, Zortuk M, Asyali MH, Sisman Y, Kilinc HI, Ertas ET. Effect of chewing on dental patients with total denture: an experimental study. Springerplus. 2013;2(1):40. 
35. Albert TE, Buschang PH, Throckmorton GS. Masticatory performance: a protocol for standardized production of an artificial test food. J Oral Rehabil. 2003;30(7):720-2.

36. Sanchez-Ayala A, Vilanova LS, Costa MA, Farias-Neto A. Reproducibility of a silicone-based test food to masticatory performance evaluation by different sieve methods. Braz Oral Res. 2014;28.

37. Sugiura T, Fueki K, Igarashi Y. Comparisons between a mixing ability test and masticatory performance tests using a brittle or an elastic test food. J Oral Rehabil. 2009;36(3):159-67.

38. Plesh O, Bishop B, McCall W. Effect of gum hardness on chewing pattern. Exp Neurol. 1986;92(3):502-12.

39. Hayasaki H, Saitoh I, Throckmorton GS, Iwase Y, Nakata S, Nakata M. Occlusal phase of gum-chewing strokes. J Oral Rehabil. 2003;30(10):1041-6.

40. Shiga H, Stohler CS, Kobayashi Y. The effect of bolus size on the chewing cycle in humans. Odontology. 2001;89(1):49-53.

41. Blissett A, Prinz JF, Wulfert F, Taylor AJ, Hort J. Effect of bolus size on chewing, swallowing, oral soft tissue and tongue movement. J Oral Rehabil. 2007;34(8):572-82.

42. Mazari A, Heath MR, Prinz JF. Contribution of the cheeks to the intraoral manipulation of food. Dysphagia. 2007;22(2):117-21.

43. Fontijn-Tekamp FA, Slagter AP, Van Der Bilt A, Van THMA, Witter DJ, Kalk W, et al. Biting and chewing in overdentures, full dentures, and natural dentitions. J Dent Res. 2000;79(7):1519-24.
44. Slagter AP, Bosman F, Van der Bilt A. Comminution of two artificial test foods by dentate and edentulous subjects. J Oral Rehabil. 1993;20(2):159-76.

45. Mancuso DN, Goiato MC, Gennari Filho H, Gomes EA. Bite force and masticatory efficiency in implant-retained dentures: literature review. Dent Today. 2008;27(8):56-8; quiz 9.

46. Fontijn-Tekamp FA, Slagter AP, Van der Bilt A, Van't Hof MA, Kalk W, Jansen JA. Swallowing thresholds of mandibular implant-retained overdentures with variable portion sizes. Clin Oral Implants Res. 2004;15(3):375-80.

47. Slagter AP, Olthoff LW, Steen WH, Bosman F. Comminution of food by complete-denture wearers. J Dent Res. 1992;71(2):380-6.

48. Chen L, Xie Q, Feng H, Lin Y, Li J. The masticatory efficiency of mandibular implant-supported overdentures as compared with tooth-supported overdentures and complete dentures. J Oral Implantol. 2002;28(5):238-43.

49. Ibraheem EM, Nassani MZ. The effect of flexible acrylic resin on masticatory muscle activity in implant-supported mandibular overdentures: a controlled clinical trial. Electron Physician. 2016;8(1):1752-8.

50. Hazari P, Bhoyar A, Mishra SK, Yadav NS, Mahajan H. A Comparison of Masticatory Performance and Efficiency of Complete Dentures Made with High Impact and Flexible Resins: A Pilot Study. J Clin Diagn Res. 2015;9(6):ZC29-34.

51. Berretin-Felix G, Nary Filho H, Padovani CR, Trindade Junior AS, Machado WM. Electromyographic evaluation of mastication and swallowing in elderly individuals with mandibular fixed implant-supported prostheses. J Appl Oral Sci. 2008;16(2):116-21. 